\title{
Contract Strategies in Competing Supply Chains with Risk-Averse Suppliers
}

\author{
Baixun Li, ${ }^{1}$ Yongwu Zhou, ${ }^{2}$ and Baozhuang Niu ${ }^{3}$ \\ ${ }^{1}$ School of Business Administration, Guangdong University of Finance and Economics, Guangzhou 510320, China \\ ${ }^{2}$ School of Business Administration, South China University of Technology, Guangzhou 510640, China \\ ${ }^{3}$ Lingnan College, Sun Yat-sen University, Guangzhou 510275, China
}

Correspondence should be addressed to Baozhuang Niu; niubzh@mail.sysu.edu.cn

Received 2 August 2013; Accepted 22 September 2013

Academic Editor: Tsan-Ming Choi

Copyright (C) 2013 Baixun Li et al. This is an open access article distributed under the Creative Commons Attribution License, which permits unrestricted use, distribution, and reproduction in any medium, provided the original work is properly cited.

\begin{abstract}
This paper investigates the equilibrium contract strategies of two competing supply chains. Each chain is composed of one riskaverse supplier and one risk-neutral retailer. The two suppliers, as Stackelberg leaders, can choose either wholesale price or revenue sharing contract. We compare the outcomes obtained from different scenarios and study the impact of competition density and risk attitudes on the suppliers' contract choices. We find that it is always optimal for the first-moving supplier to choose revenue sharing contract if the follower chooses wholesale price contract. We also find that the retail price under revenue sharing contract is lower than that under wholesale price contract. Compared to Pan et al. (2010), we find that a threshold policy with respect to the degree of product substitutability holds in a sequential competition environment. There also exists a threshold policy with respect to the degree of risk aversion for the suppliers to choose their individual contract types and the corresponding chain-to-chain contract strategies.
\end{abstract}

\section{Introduction}

Nowadays, with the development of information technology, many "pure" service companies have arisen, such as Expedia, Alibaba.com, Crip.com, and China Mobile. In these companies, no physical products are sold-what they can provide are intangible products, that is, services. Even some companies, who traditionally produce and sell physical products, are changing to be service providers. One typical example is IBM, who uses its LotusLive Connections to apply a new business model named "Software-as-a-Service (SaaS)", under which customers need only "pay a subscription fee to use a software over the internet" [1]. To find more customers, these service companies rely on agents/retailers and hence form service supply chains. For example, China Mobile contracts with agents to sell its telecommunication services. As the key supply chain member, China Mobile is very powerful. They determine the service charges, the service contracts, and so on. Retailers just follow China Mobile's decisions to earn some agent fee.
Similar phenomena can be observed in nonservice supply chains. For example, in the petrol retailing industry, Caffarra and Mattei [2] find that UK oil companies hold the right of selecting the organizational structures (and hence the contract parameters such as the wholesale price) in their retail networks. It is suggested that the petrol suppliers would be significantly "rewarded or penalized" according to their contract strategies. For the other industries, such as the electronic industry $[3,4]$, the television industry [5], and the agriculture industry [6], the determination of contract type and/or parameters are continuously discussed and investigated. This indicates that the competing suppliers, especially those who sell their products through retailers, must be very careful at the contract design stage so as to gain some competitive advantages.

In practice, different suppliers may choose different kinds of contracts with retailers. A variety of contractual relationships have been discussed in the literature, for example, wholesale-price contract [7], revenue sharing contract [8], quantity-discount contract [9], and consignment contract 
[10]. See Cachon [11] for the literature review on supply chain contracts. Among these studies, we note that Pan et al. [8] study the contract choice problems (revenue sharing versus wholesale price) by assuming two competing manufacturers make their decisions simultaneously, which is reasonable but ignores the more common sequential-moving supply chains. Therefore, in this paper, we relax their assumption and examine scenarios where suppliers have imbalanced power, so that suppliers can act as Stackelberg leaders. Such supply chains can be found in many industries, for example, the domestic appliance industry, tourism industry, telecommunication industry, and beverage industry. Moreover, we note that more and more suppliers are concerning the loss minimization of their companies; thus, it is important to investigate the role of risk aversion in the competing supply chains. Tsay [12] points out that the "risk sensitivity" has an important impact on the decisions of the supply chain members. However, few studies have addressed risk aversion in chain-to-chain competition environments. Thus, in this paper, we relax the risk-neutral assumption of Pan et al. [8] to examine scenarios where suppliers are risk-averse, and analyze the effects of the degree of risk aversion on the suppliers' contract decisions. Readers hence can view this paper as an extension of that of Pan et al. [8] with the consideration of sequential-moving supply chains and riskaverse suppliers.

Our analysis leads to the following insights. (I) Revenue sharing contract is the best option for the first-moving supplier if the follower chooses wholesale price contract, regardless of the degree of competition density and risk aversion. However, if the follower chooses revenue sharing contract, it is possible for the leader to choose wholesale price contract. (II) There exist threshold policies with respect to the degree of competition density and risk aversion for the suppliers to choose contract strategies. The retail price under revenue sharing contract is lower than that under wholesale price contract. Thus, if the follower could not afford the loss due to low retail price, he/she has incentives to switch to wholesale price contract.

The remainder of this paper is organized as follows. Section 2 briefly reviews related literature. Section 3 presents our basic model. Section 4 derives close form equilibrium solutions for different contract structures, including the WW, WR, RW, and RR cases. Section 5 compares the equilibrium profits under different cases and identifies the conditions under which the suppliers should choose wholesale price contract or revenue sharing contract. Finally, we summarize the paper and suggest research extensions in Section 6.

\section{Literature Review}

This paper is related to the work on chain-to-chain competition. McGuire and Staelin [13] investigate the effect of product substitutability on the suppliers' decision of integrating with an outside retailer or not. Trivedi [14] looks into two manufacturers and two common retailers and analyzes the effect of product and channel substitution. Boyaci and Gallego [15] consider a market comprising two supply chains and explore the value and limitation of channel coordination. Wu et al. $[16,17]$ extend the seminal work of McGuire and Staelin [13] by considering demand uncertainty. They build competitive newsvendor models to investigate the channel design problems. Allon and Federgruen [18] build multiple stage models to study competition in the service industries. Shou et al. [19] study the chain-to-chain competition problems with the consideration of supply uncertainty. Chiu et al. [20] consider price-dependent demand and study methods to avoid price war among multiple retailers. Xie et al. [21] consider the selection of supply chain structures and quality improvement strategies of two supply chains. Li et al. [22] investigate the channel choice problem in two competing supply chains with asymmetric cost information. Different from the aforementioned literature, we study the contract strategies with the consideration of sequential-moving supply chains and risk-averse suppliers.

The literature on supply chain contract is also related. Cachon [11] gives an excellent review on supply chain contract and coordination. This work has extensively reviewed the one-to-one or one-to-N supply chain structures (see, e.g, [2325]). One conclusion is that the wholesale-price contract is Pareto inferior for the supply chain, which leads to the double marginalization effect. To eliminate the double marginalization effect, manufacturers need to design sophisticated contracts, such as quantity flexibility contract, quantity discount contract, and revenue sharing contract. However, are sophisticated contracts always better for all the supply chains?

Recently, some papers find that the degree of competition has a significant impact on the contract choice decision. $\mathrm{Ha}$ and Tong [26] investigate contracting and information sharing problems in two competing supply chains. They highlight that contract type is a key driver of the value of information sharing. Differing from $\mathrm{Ha}$ and Tong [26], $\mathrm{Ha}$ et al. [27] assume imperfect demand signals, production diseconomy, and both Cournot and Bertrand competition with differentiated products. Cachon and Kök [9] study the problem of contract choice in the supply chain structure comprising two competing manufacturers and a single retailer. They show that sophisticated contracts (e.g., quantity discount, two-part tariff contract) may make manufacturers worse off and the retailer substantially better off. Pan et al. [8] discuss different contract strategies (wholesale price contract versus revenue sharing contract) under both manufacturer dominated and retailer dominated scenarios in a supply chain with either two-one structure or one-two structure. Zhao and Shi [10] consider two supply chains, each with multiple upstream suppliers producing complementary products and selling to a single buyer. They focus on the channel structure (integration versus decentralization) issues and the contract strategies (wholesale price contract versus revenue sharing contract) issues. Ai et al. [28] demonstrate the impact of demand uncertainty and retailers' forecasting precision on contract decisions of the manufacturers in two competing supply chains. Feng and Lu [7] analyze contract strategies in a supply chain comprising two competing manufacturers and two competing retailers. They derive the outcomes of Stackelberg games via generalized Nash bargaining scheme. Li et al. [29] explore the effect of supply chain structure 
and competition at both manufacturer and retailer levels on contract choices of two competing supply chains.

In the literature above, most studies assume that manufacturers are risk-neutral. When facing random demand, however, the manufacturers will be more concerned with the risk associated with demand uncertainties. The inclusion of risk into decision making has gained increasing interest in supply chain studies (e.g., [30-34]). Different methods have been used to study risk aversion; for example, Hsieh and $\mathrm{Lu}$ [35] characterize each retailer's risk-embedded objects and compare them with conditional value-at-risk. They study the manufacturer's return policy and the retailers' decisions. Caliskan-Demirag et al. [36] model risk aversion by adopting the conditional-value-at-risk (CVaR) decision criterion, and analyze the manufacturer's rebate amount decisions and the retailer's joint inventory and pricing decisions.

Some other papers develop the risk aversion model in a mean-variance framework. Chen and Seshadri [37] consider a single period model in which multiple risk-averse retailers purchase a single product from a common distributor with a mean-variance utility approach. Choi et al. [38] carry out a mean-variance analysis of the newsvendor problems. Choi and Chow [39] study quick response program using a meanvariance approach. Xiao and Choi [40] focus on channel structure strategies in a two-echelon system consisting of two manufacturers and two retailers, where all players are riskaverse. Wei and Choi [32] explore the use of wholesale price contract and profit sharing contract to coordinate supply chains under the mean-variance decision framework. Chiu et al. [41] carry out a mean-variance analysis of supply chains under target sales rebate contracts. Chiu et al. [42] explore the performance of sales rebate contract in fashion supply chains under a mean-variance framework. Ma et al. [43] examine the impact of bargaining powers and the retailer's risk attitudes using a CVaR framework. Li et al. [44] conduct a mean variance analysis of a fast fashion supply chain with return policy. $\mathrm{Ma}$ et al. [45] study the inventory control problem for a loss-averse retailer with financial constraint in a finite periodic review system. Shen et al. [46] explore how markdown money policy performs in a two-stage TC/fashion supply chain with an upstream risk-averse manufacturer and a downstream risk-neutral retailer under the mean-variance framework. See Chiu and Choi [47] for an excellent review of this line of literature.

Our paper is most closely related to Cachon and Kök [9], Pan et al. [8], Feng and Lu [7], and Li et al. [29]. We extend their models in two dimensions. First, we examine scenarios where manufacturers have imbalanced power, so that manufacturers can move first. Second, we examine scenarios where manufacturers are risk-averse and investigate the impact of the degree of risk aversion on the contract choice decisions. Referring to Xiao and Choi [40], we model the risk aversion with mean-variance utility functions in this paper.

\section{Model Settings}

Consider a market in which two supply chains (denoted by $\mathrm{SC}_{1}$ and $\mathrm{SC}_{2}$ ) compete with each other. Each supply chain is composed of a single supplier (denoted by $\mathrm{M}_{i}, i=$ 1,2 ) and a single exclusive retailer (denoted by $\mathrm{R}_{i}, i=$ $1,2)$. Without loss of generalization, we assume $\mathrm{SC}_{1}$ is the market leader who produces and launches a product first. This is a common phenomenon in practice, for example, China Mobile launches its M-Zone service earlier than China Unicom, whose competing product is Up-Power (admittedly, it is possible to investigate the timing decisions of the two supply chains, named as endogenous leadership game; see Wang et al. [3, 4, 48] for further information. However, here our focus is the contract type choice and the impact of risk attitudes we leave the timing decisions for future research). We assume the two chains compete strictly in retail price, $p_{i}$, which directly determines their respective customer demand, $\widetilde{D_{i}}$. Referring to McGuire and Staelin [13], we assume the following linear demand function:

$$
\widetilde{D_{i}}=\widetilde{A_{i}}-p_{i}+\theta p_{3-i},
$$

where $i=1,2 . \widetilde{A_{i}}$ denotes the stochastic market potential for product $i$, with the mean $\overline{A_{i}}>0$ and variance $\sigma_{i}^{2}$. The parameter $\theta \in(0,1)$ represents the degree of product substitutability, which can be viewed as a measurement of demand competition density [26]. When $\theta \rightarrow 0$, there is no cross market influence, implying that the products are independent. When $\theta \rightarrow 1$, there is a perfect product substitution.

Towards the contract types adopted in each supply chain, we consider wholesale price contract (denoted by W) and revenue sharing contract (denoted by $\mathrm{R}$ ). The reasons for choosing these two contract types are as follows. First, both wholesale price contract and revenue sharing contract are widely studied and used in theory and practice; we can thus compare our results directly with previous literature such as Pan et al. [8] and Zhao and Shi [10]. Second, these contract types represent the "simple" contract and the "sophisticated" contract, respectively.

Under a wholesale price contract, $w_{i}$ is the wholesale price of product $i, p_{i}$ is the retail price, and $u_{i}$ is the unit profit margin of retailer $i$, where $u_{i}=p_{i}-w_{i}$. Under a revenue sharing contract, the retailer keeps a portion of channel revenue $\left(\phi_{i} p_{i}\right)$, and $\left(1-\phi_{i}\right) p_{i}$ is the fraction the supplier earns. Moreover, as Pan et al. [8] have pointed out, the supplier who chooses a revenue-sharing contract should make sure that the retailer's profit for each unit of product sold is not less than the marginal profit under a wholesale price contract, that is, $\phi_{i} p_{i}-w_{i} \geq u_{i}$. As the leader of a supply chain, service providers are authorized to decide whether wholesale price contract or revenue sharing contract should be offered to the exclusive retailer. Similar assumption has been made by Pan et al. [8]. Combing the suppliers' choices, in the two supply chains, there will be four possible scenarios: WW, WR, RW, and RR, where WW denotes that two supply chains are restricted to choose the wholesale price contract; WR means that supplier $1\left(\mathrm{M}_{1}\right)$ chooses the wholesale-price contract, while supplier $2\left(\mathrm{M}_{2}\right)$ chooses the revenue sharing contract. RW and RR are similar. Our model includes a two-level game. On the one hand, there is a Stackelberg game between $\mathrm{SC}_{1}$ and $\mathrm{SC}_{2}$. The market leader $\mathrm{SC}_{1}$ determines his/her contract 
strategies to maximize its own profit, anticipating the follower $\mathrm{SC}_{2}$ 's possible actions. On the other hand, the individual members of each supply chain maximize their own profits, and there is a Stackelberg relationship between the supplier and the retailer.

In particular, similar to Xiao and Choi [40] and Choi et al. [49], we model the risk attitudes of the suppliers with meanvariance utility function as follows:

$$
U_{\mathrm{M}_{i}}^{l}\left(\pi_{\mathrm{M}_{i}}^{l}\right)=E\left(\pi_{\mathrm{M}_{i}}^{l}\right)-\lambda_{i} \operatorname{Var}\left(\pi_{\mathrm{M}_{i}}^{l}\right),
$$

where $U_{\mathrm{M}_{i}}^{l}\left(\pi_{\mathrm{M}_{i}}^{l}\right)$ denotes the utility function of supplier $i$ and $E\left(\pi_{\mathrm{M}_{i}}^{l}\right)$ and $\operatorname{Var}\left(\pi_{\mathrm{M}_{i}}^{l}\right)$ represent the mean and the variance of supplier $i$ 's expected profit, respectively. $l=\mathrm{WW}, \mathrm{WR}$, $\mathrm{RW}$, and RR and the parameter $\lambda_{i} \geq 0$ denotes the constant absolute risk aversion of supplier $i$. The larger $\lambda_{i}$ is, the more conservative supplier $i$ 's behavior will be.

\section{Equilibrium Solutions}

In this section, we derive the close form solutions for different contract structures, including WW, WR, RW, and RR. We use backward induction to find the equilibriums for all of the participants.

4.1. Symmetric Subgame 1: $W W$. In the WW case, both $\mathrm{M}_{1}$ and $\mathrm{M}_{2}$ are restricted to choose wholesale price contracts. We consider $\mathrm{SC}_{2}$ 's decisions first. Given wholesale price $w_{2}^{\mathrm{WW}}$, $\mathrm{R}_{2}$ determines $u_{2}^{\mathrm{WW}}$ (note that $u_{i}^{\mathrm{WW}}=p_{i}^{\mathrm{WW}}-w_{i}^{\mathrm{WW}}$, so $\mathrm{R}_{i}$ 's decision of $u_{i}^{\mathrm{WW}}$ is equivalent to the decision of retail price $p_{i}^{\mathrm{WW}}$ ) by maximizing his/her expected profit:

$$
\begin{aligned}
& \max _{u_{2}^{\mathrm{WW}} \geq 0} \pi_{R 2}^{\mathrm{WW}} \\
& \quad=u_{2}^{\mathrm{WW}}\left[\overline{A_{2}}-\left(u_{2}^{\mathrm{WW}}+w_{2}^{\mathrm{WW}}\right)+\theta\left(u_{1}^{\mathrm{WW}}+w_{1}^{\mathrm{WW}}\right)\right] .
\end{aligned}
$$

It can be shown that $\pi_{R 2}^{\mathrm{WW}}$ is concave with respect to $u_{2}^{\mathrm{WW}}$; thus, the best response $u_{2}^{\mathrm{WW}}$ can be written as

$$
u_{2}^{* \mathrm{WW}}\left(w_{2}^{\mathrm{WW}}, u_{1}^{\mathrm{WW}}, w_{1}^{\mathrm{WW}}\right)=\frac{\overline{A_{2}}-w_{2}^{\mathrm{WW}}+\theta\left(u_{1}^{\mathrm{WW}}+w_{1}^{\mathrm{WW}}\right)}{2} .
$$

Anticipating the $\mathrm{R}_{2}$ 's actions, $\mathrm{M}_{2}$ determines wholesale price to maximize his/her utility:

$$
\begin{aligned}
& \max _{w_{2}^{\mathrm{WW}} \geq 0} U_{\mathrm{M}_{2}}^{\mathrm{WW}}\left(\pi_{\mathrm{M}_{2}}^{\mathrm{WW}}\right) \\
& \quad=\left(w_{2}^{\mathrm{WW}}-c_{2}\right) \times D_{2}\left(u_{2}^{* \mathrm{WW}}\right)-\frac{1}{2} \lambda_{2} \sigma_{2}^{2}\left(w_{2}^{\mathrm{WW}}-c_{2}\right)^{2},
\end{aligned}
$$

where $c_{i}$ denotes the manufacturing cost of product $i, i=1,2$. The first-order condition of (5) leads to the best response wholesale price:

$$
w_{2}^{* \mathrm{WW}}\left(u_{1}^{\mathrm{WW}}, w_{1}^{\mathrm{WW}}\right)=c_{2}+\frac{\overline{A_{2}}-c_{2}+\theta\left(u_{1}^{\mathrm{WW}}+w_{1}^{\mathrm{WW}}\right)}{2+2 \lambda_{2} \sigma_{2}^{2}} .
$$

We now turn to $\mathrm{SC}_{1}$ 's decisions. Anticipating $\mathrm{SC}_{2}$ 's actions, $\mathrm{M}_{1}$ and $\mathrm{R}_{1}$ of $\mathrm{SC}_{1}$ determine their best responses sequentially. Using similar event sequence, we derive the equilibriums with respect to $u_{1}^{\mathrm{WW}}$ and $w_{1}^{\mathrm{WW}}$. For the convenience, let $\Delta_{i}=1+\lambda_{i} \sigma_{i}^{2}, i=1,2$. We have

$$
\begin{aligned}
u_{1}^{* \mathrm{WW}}\left(w_{1}^{\mathrm{WW}}\right) & \\
= & \frac{4 \Delta_{2} \overline{A_{1}}+2 \theta \Delta_{2} \overline{A_{2}}+\theta\left(2 \Delta_{2} c_{2}-c_{2}+\overline{A_{2}}\right)}{4 \Delta_{2} \theta^{2}+2 \theta^{2}-8 \Delta_{2}} \\
& +\frac{\left(\theta^{2}+2 \Delta_{2} \theta^{2}-4 \Delta_{2}\right) w_{1}^{\mathrm{WW}}}{4 \Delta_{2} \theta^{2}+2 \theta^{2}-8 \Delta_{2}}, \\
w_{1}^{* \mathrm{WW}} & \\
= & \frac{2 \Delta_{2}\left(2 c_{1}+2 \overline{A_{1}}+4 c_{1} \lambda_{1} \sigma_{1}^{2}-c_{1} \theta^{2}+\theta \overline{A_{2}}+\theta c_{2}\right)}{8 \Delta_{1} \Delta_{2}-2 \theta^{2}\left(2 \Delta_{2}+1\right)} \\
& +\frac{\theta\left(\bar{A}_{2}-c_{2}-c_{1} \theta\right)}{8 \Delta_{1} \Delta_{2}-2 \theta^{2}\left(2 \Delta_{2}+1\right)} .
\end{aligned}
$$

We use superscript WW to represent the optimal solutions in the WW case. Substituting $w_{1}^{* \mathrm{WW}}$ back to $u_{1}^{* \mathrm{WW}}\left(w_{1}^{\mathrm{WW}}\right), w_{2}^{* \mathrm{WW}}\left(u_{1}^{\mathrm{WW}}, w_{1}^{\mathrm{WW}}\right), u_{2}^{* \mathrm{WW}}\left(w_{2}^{\mathrm{WW}}, u_{1}^{\mathrm{WW}}, w_{1}^{\mathrm{WW}}\right)$, we get all the equilibriums $u_{1}^{* \mathrm{WW}}, w_{2}^{* \mathrm{WW}}, u_{2}^{* \mathrm{WW}}$ and the corresponding production quantities and profits.

4.2. Hybrid Subgame 1: WR. The WR case represents that the $M_{1}$ chooses wholesale price contract while the $M_{2}$ chooses revenue sharing contract. Similar to the WW case, we first analyze $\mathrm{SC}_{2}$ 's decisions. As pointed out by Pan et al. [8], under a revenue sharing contract, the supplier $M_{2}$ should

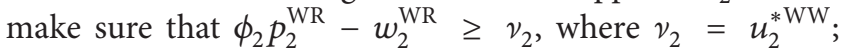
otherwise, the retailer will prefer a wholesale price contract to a revenue sharing contract. As for $\mathrm{M}_{2}$, he/she expects that the retailer shares the revenue as small as possible such that $\phi_{2}^{\mathrm{WR}} p_{2}^{\mathrm{WR}}-w_{2}^{\mathrm{WR}}=v_{2}$. Therefore, given $\phi_{2}^{\mathrm{WR}}$, the decision of $p_{2}^{\mathrm{WR}}$ and $w_{2}^{\mathrm{WR}}$ is equivalent. The profit maximization problem of $\mathrm{M}_{2}$ is

$$
\begin{aligned}
\max _{p_{2}^{\mathrm{WR}} \geq 0} & U_{\mathrm{M}_{2}}^{\mathrm{WR}}\left(\pi_{\mathrm{M}_{2}}^{\mathrm{WR}}\right) \\
= & \left(p_{2}^{\mathrm{WR}}-c_{2}-v_{2}\right)\left[\overline{A_{2}}-p_{2}^{\mathrm{WR}}+\theta\left(w_{1}^{\mathrm{WR}}+u_{1}^{\mathrm{WR}}\right)\right] \\
& -\frac{1}{2} \lambda_{2} \sigma_{2}^{2}\left(p_{2}^{\mathrm{WR}}-c_{2}-v_{2}\right)^{2} .
\end{aligned}
$$

The first-order condition of (8) leads to the best response $p_{2}^{*}$ :

$$
\begin{aligned}
& p_{2}^{* \mathrm{WR}}\left(u_{1}^{\mathrm{WR}}, w_{1}^{\mathrm{WR}}\right) \\
&=c_{2}+v_{2}+\frac{\overline{A_{2}}-c_{2}-v_{2}+\theta\left(u_{1}^{\mathrm{WR}}+w_{1}^{\mathrm{WR}}\right)}{2+\lambda_{2} \sigma_{2}^{2}} .
\end{aligned}
$$


Then, $\mathrm{M}_{1}$ and $\mathrm{R}_{1}$ of $\mathrm{SC}_{1}$ determine their best response conditional on the response of $\mathrm{SC}_{2}, p_{2}^{* \mathrm{WR}}\left(u_{1}^{\mathrm{WR}}, w_{1}^{\mathrm{WR}}\right)$. It can be shown that

$$
\begin{aligned}
& u_{1}^{* \mathrm{WR}}\left(w_{1}^{\mathrm{WR}}\right) \\
& =\frac{\left(1+\Delta_{2}\right)\left(\overline{A_{1}}-w_{1}^{\mathrm{WR}}\right)}{2\left[\left(1+\Delta_{2}\right)-\theta^{2}\right]} \\
& +\frac{\theta\left(\bar{A}_{2}+c_{2} \Delta_{2}+v_{2} \Delta_{2}+\theta w_{1}^{\mathrm{WR}}\right)}{2\left[\left(1+\Delta_{2}\right)-\theta^{2}\right]}, \\
& w_{1}^{* \mathrm{WR}} \\
& =\frac{\theta\left[\overline{A_{2}}-c_{1} \theta+\Delta_{2}\left(c_{2}+v_{2}\right)\right]}{2\left[\Delta_{1}\left(1+\Delta_{2}\right)-\theta^{2}\right]} \\
& +\frac{\left(1+\Delta_{2}\right)\left(\overline{A_{1}}-c_{1}+2 c_{1} \Delta_{1}\right)}{2\left[\Delta_{1}\left(1+\Delta_{2}\right)-\theta^{2}\right]} \text {. }
\end{aligned}
$$

We use superscript WR to represent the optimal solutions in the WR case. Substituting $w_{1}^{* \mathrm{WR}}$ into $u_{1}^{* \mathrm{WR}}\left(w_{1}^{\mathrm{WR}}\right)$ and $p_{2}^{* \mathrm{WR}}\left(u_{1}^{\mathrm{WR}}, w_{1}^{\mathrm{WR}}\right)$ yields all the equilibriums in the WR case.

4.3. Hybrid Subgame 2: RW. The RW case represents that $M_{1}$ chooses revenue sharing contract while $M_{2}$ chooses wholesale price contract. The detail of solution process is similar to that in WR case. The best responses $u_{2}^{\mathrm{RW}}, w_{2}^{\mathrm{RW}}$, and $p_{1}^{\mathrm{RW}}$ are given by

$$
\begin{gathered}
u_{2}^{* \mathrm{RW}}\left(w_{2}^{\mathrm{RW}}, p_{1}^{\mathrm{RW}}\right)=\frac{\overline{A_{2}}-w_{2}^{\mathrm{RW}}+\theta p_{1}^{\mathrm{RW}}}{2} \\
w_{2}^{* \mathrm{RW}}\left(p_{1}^{\mathrm{RW}}\right)=c_{2}+\frac{\overline{A_{2}}-c_{2}+\theta p_{1}^{\mathrm{RW}}}{2+2 \lambda_{2} \sigma_{2}^{2}}, \\
p_{1}^{* \mathrm{RW}} \\
=\frac{2 \Delta_{2}\left(2 \overline{A_{1}}+\theta \overline{A_{2}}\right)+\theta\left(2 c_{2} \Delta_{2}-c_{2}+\overline{A_{2}}\right)}{2\left[2 \Delta_{1} \Delta_{2}-\theta^{2}\left(1+2 \Delta_{2}\right)+2 \Delta_{2}\right]}, \\
-\frac{\left(c_{1}+v_{1}\right)\left(2 \theta^{2} \Delta_{2}+\theta^{2}-4 \Delta_{2}+4 \Delta_{2} \lambda_{1} \sigma_{1}^{2}\right)}{2\left[2 \Delta_{1} \Delta_{2}-\theta^{2}\left(1+2 \Delta_{2}\right)+2 \Delta_{2}\right]},
\end{gathered}
$$

where $\nu_{1}=u_{1}^{* \mathrm{WW}}$. Substituting $p_{1}^{* \mathrm{RW}}$ into $w_{2}^{* \mathrm{RW}}\left(p_{1}^{\mathrm{RW}}\right)$ and $u_{2}^{* \mathrm{RW}}\left(w_{2}^{\mathrm{RW}}, p_{1}^{\mathrm{RW}}\right)$ yields all the equilibriums in the RW case.

4.4. Symmetric Subgame 2: RR. The RR case represents that both $M_{1}$ and $M_{2}$ choose revenue sharing contract. Note that $M_{1}$ and $M_{2}$ have to guarantee $R_{1}$ and $R_{2}$ to obtain at least the same profits as those they can obtain under a wholesale price contract. We derive the best response retail price of $\mathrm{SC}_{2}$ first as

$$
p_{2}^{* \mathrm{RR}}\left(p_{1}^{\mathrm{RR}}\right)=c_{2}+v_{2}+\frac{\overline{A_{2}}-c_{2}-v_{2}+\theta p_{1}^{\mathrm{RR}}}{2+2 \lambda_{2} \sigma_{2}^{2}}
$$

Anticipating the $\mathrm{SC}_{2}$ 's actions, $\mathrm{SC}_{1}$ determines his best response $p_{1}^{\mathrm{RR}}$ as

$$
\begin{aligned}
p_{1}^{* \mathrm{RR}} & \\
= & \frac{2 \Delta_{2} \overline{A_{1}}-\left(c_{1}+v_{1}\right)\left(\theta^{2}-2 \Delta_{2}+4 \Delta_{2} \lambda_{1} \sigma_{1}^{2}\right)}{2\left(2 \Delta_{2}-\theta^{2}+\Delta_{2} \lambda_{1} \sigma_{1}^{2}\right)} \\
& +\frac{\theta\left[\left(2 \Delta_{2}-1\right)\left(c_{2}+v_{2}\right)+\overline{A_{2}}\right]}{2\left(2 \Delta_{2}-\theta^{2}+\Delta_{2} \lambda_{1} \sigma_{1}^{2}\right)} .
\end{aligned}
$$

Substituting $p_{1}^{* \mathrm{RR}}$ back yields all the equilibriums in the RR case.

\section{Analysis of Contract Strategies}

In this section, we compare the suppliers' equilibrium profits under different cases and identify the conditions under which they choose wholesale price contract or revenue sharing contract. We also would like to find the equilibrium contract structure. According to previous literatures such as Choi et al. [38], Xiao and Choi [40], and Pan et al. [8], the degree of product substitutability and risk attitudes are the critical factors; therefore, we assume a symmetric scenario in the sense that $\overline{A_{1}}=\overline{A_{2}}=\bar{A}, \sigma_{1}=\sigma_{2}=\sigma, c_{1}=c_{2}=$ c. Then their impacts are ruled out, leaving $\mathrm{M}_{1}$ and $\mathrm{M}_{2}$ differing from each other via their risk attitudes: $\lambda_{1}$ and $\lambda_{2}$. We find that under this assumption, all of the optimal $U_{\mathrm{M}_{i}}^{l}$, $l=\mathrm{WW}, \mathrm{WR}, \mathrm{RW}, \mathrm{RR}, i=1,2$, can be expected as a function of a common factor $(\bar{A}-c+c \theta)^{2}$. Then, the comparison of the utilities depends only on three parameters: the degree of product substitutability $(\theta)$, the degree of risk aversion $\left(\lambda_{i}\right)$, and the variance of stochastic market base $(\sigma)$. Moreover, the parameters $\lambda_{i}$ and $\sigma$ always arise together with the form of $\lambda_{i} \sigma^{2}$, therefore, to focus on the impact of risk aversion, we first set $\sigma$ as a given positive constant. Next we investigate how the degree of product substitutability and the risk attitudes of the suppliers influence the supply chain contract decisions and compare our results with the previous literature. We analyze symmetric and asymmetric risk attitudes of the two suppliers.

5.1. Impact of Product Substitutability (Risk-Neutral Suppliers). To obtain analytical comparison results with respect to the degree of product substitutability, we assume $\lambda_{1}=\lambda_{2}=$ $\lambda=0$, in other words, both suppliers are risk-neutral. We analyze the incentive of a supplier to switch from wholesale price contract (revenue sharing contract) to revenue sharing contract (wholesale price contract). Lemmas 1 and 2 describe $M_{1}$ 's $\left(M_{2}\right.$ 's) preference given $M_{2}$ 's $\left(M_{1}\right.$ 's) choice.

Lemma 1. From $M_{1}$ 's perspective, (i) if $M_{2}$ chooses wholesale price contract, then it is optimal for $M_{1}$ to choose revenue sharing contract. $\theta$ has no impact. (ii) If $M_{2}$ chooses revenue sharing contract, then $M_{1}$ is better to choose revenue sharing contract when $0<\theta \leq 0.69$, otherwise, wholesale price contract. 
TABLE 1: Stability analysis of risk-neutral suppliers' perspectives.

\begin{tabular}{|c|c|c|c|c|}
\hline \multirow{2}{*}{ Original structure } & \multicolumn{2}{|c|}{$\mathrm{M}_{1}$} & \multicolumn{2}{|c|}{$\mathrm{M}_{2}$} \\
\hline & New structure & Change in profits & New structure & Change in profits \\
\hline \multirow{2}{*}{ WW } & \multirow{2}{*}{ RW } & \multirow{2}{*}{$0<\theta<1, \uparrow^{*}$} & \multirow{2}{*}{ WR } & $0<\theta \leq 0.55, \uparrow$ \\
\hline & & & & $0.55<\theta<1, \downarrow$ \\
\hline \multirow{2}{*}{ RW } & \multirow{2}{*}{ WW } & \multirow{2}{*}{$0<\theta<1, \downarrow$} & \multirow{2}{*}{$\mathrm{RR}$} & $0<\theta \leq 0.51, \uparrow$ \\
\hline & & & & $0.51<\theta<1, \downarrow$ \\
\hline \multirow{2}{*}{ WR } & \multirow{2}{*}{$\mathrm{RR}$} & $0<\theta \leq 0.69, \uparrow$ & \multirow{2}{*}{ WW } & $0<\theta \leq 0.55, \downarrow$ \\
\hline & & $0.69<\theta<1, \downarrow$ & & $0.55<\theta<1, \uparrow$ \\
\hline \multirow{2}{*}{$\mathrm{RR}$} & \multirow{2}{*}{ WR } & $0<\theta \leq 0.69, \downarrow$ & \multirow{2}{*}{ RW } & $0<\theta \leq 0.51, \downarrow$ \\
\hline & & $0.69<\theta<1, \uparrow$ & & $0.51<\theta<1, \uparrow$ \\
\hline
\end{tabular}

*When the utility of new structure is more than the original structure, we denote it by " $\uparrow$ ", otherwise, " $\downarrow$ ".

Lemma 2. From $M_{2}$ 's perspective, (i) if $M_{1}$ chooses wholesale price contract, then $M_{2}$ is better off with revenue sharing contract under $0<\theta \leq 0.55$, otherwise, wholesale price contract. (ii) If $M_{1}$ chooses revenue sharing contract, then $M_{2}$ is better off with revenue sharing contract under $0<\theta \leq 0.51$, otherwise, wholesale price contract.

Based on Lemmas 1 and 2, Table 1 summarizes the suppliers' incentives to switch from one structure to another one.

This leads to the equilibrium contract strategies summarized in Theorem 3.

Theorem 3. Assuming risk-neutral suppliers, the equilibrium contract strategies for the two competing supply chains is $R R$ if $\theta$ is smaller than $\hat{\bar{\theta}}$, and $R W$ otherwise.

Thus, there exists a unique threshold value of $\widehat{\bar{\theta}}$ which guides $\mathrm{M}_{2}$ 's choice of contract type. When competition is tense, that is, $\theta$ is large, it is better for $M_{2}$ to adopt a different contract type. As the degree of product substitutability decreases, competition becomes not so tense, then it is optimal for the market follower to copy the leader's strategy: adopting a revenue sharing contract. Note that, with simultaneous competition, Pan et al. [8] show that it is optimal for the suppliers to choose revenue-sharing contract when there is no tense competition. Here, we verify this finding in a sequential competition environment. The underlying reason lies in their different preferences towards the "low-price-high-volume" strategy. To further explain our findings, we compare the retail prices in different scenarios and have the following lemma.

Lemma 4. Assuming risk-neutral suppliers, the following orders always hold:

$$
p_{1}^{* R R}-p_{1}^{* W W}<0 ; \quad p_{2}^{* R R}-p_{2}^{* W W}<0 ; \quad p_{2}^{* R R}<p_{1}^{* R R} .
$$

As we show in Lemma 4, the retail price under revenue sharing contract is lower than that under wholesale price contract. Market leader has to decide a low retail price to snatch a large market share, while market follower has the right of cutting down the leader's retail price and hence

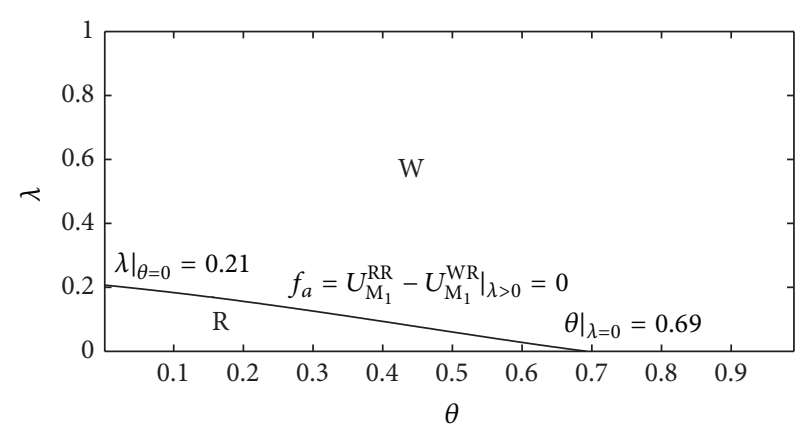

FIGURE 1: $M_{1}$ 's preference given $M_{2}$ choosing revenue sharing contract $(\lambda>0)$.

enjoys a second-mover advantage in the price competition $\left(p_{2}^{* \mathrm{RR}}<p_{1}^{* \mathrm{RR}}\right)$. This behavior will not occur when there is no information interaction under simultaneous competition, as Pan et al. [8] have studied. On the other hand, facing tense competition, the follower's profits with "low-pricehigh-volume" strategy may not compensate its loss due to low retail price. Thus, the follower has to switch to the wholesale price contract so as to enjoy a higher profit margin. This is consistent with Pan et al. [8].

5.2. Impact of Product Substitutability and Risk Attitudes (Identical Risk-Averse Suppliers). We now turn to the case $\lambda_{1}=\lambda_{2}=\lambda>0$, that is, both suppliers are riskaverse, but they are identical. With this assumption, suppliers' choices are influenced by the degree of product substitutability and risk aversion. We find that given $\mathrm{M}_{2}$ 's choice of wholesale price contract, $M_{1}$ always prefers revenue sharing contract. This is consistent with our previous finding shown in Lemma 1. However, it is not easy to analytically find $M_{1}$ 's preference when $\mathrm{M}_{2}$ chooses revenue sharing contract. We conduct numerical studies and observe similar curves; see Figure 1 for illustration. The parameters are $\bar{A}=1, \sigma=1$, $c=0.5, \lambda \in(0,1)$, and $\theta \in(0,1)$.

The rectangular area $\{(\theta, \lambda) \mid 0<\theta<1,0<\lambda<$ $1\}$ is divided into two distinct regions by the curve $f_{a}=$ $U_{\mathrm{M}_{1}}^{\mathrm{RR}}-\left.U_{\mathrm{M}_{1}}^{\mathrm{WR}}\right|_{\lambda>0}=0$, where "W" denotes that $\mathrm{M}_{1}$ prefers wholesale price contract and " $R$ " denotes that $M_{1}$ prefers 


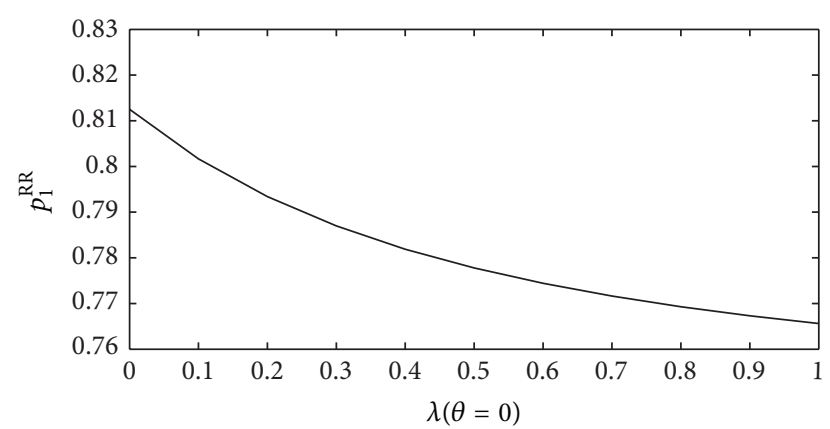

FIGURE 2: Impact of $\lambda$ on $p_{1}^{* R R}$.

revenue sharing contract. From Figure 1 we can obtain the following observations. (i) If $\lambda=0$, that is, both suppliers are risk-neutral, given $\mathrm{M}_{2}$ choosing revenue sharing contract, $\mathrm{M}_{1}$ prefers revenue sharing contract when $0<\theta \leq 0.69$, otherwise, wholesale price contract. This is consistent with Lemma 1. (ii) As the degree of risk aversion increases (e.g., $\lambda>0.21$ ), given $M_{2}$ choosing revenue sharing contract, the wholesale price contract is attractive for $M_{1}$ no matter what the value of $\theta$ is. This observation can be explained as follows. When $M_{1}$ becomes more and more conservative ( $\lambda$ becomes larger and larger), it can be observed that $p_{1}^{* \mathrm{RR}}$ is decreasing (see Figure 2). Thus, to avoid the retail price dropping too much, $M_{1}$ tends to replace the revenue sharing contract by the wholesale price contract, owing to the fact that the retail price under the revenue sharing contract is always lower than that under the wholesale price contract (see Lemma 4 and Figure 3).

We now also illustrate the follower $\mathrm{M}_{2}$ 's preference given $\mathrm{M}_{1}$ 's choice, by assuming the same numerical parameters.

Similar observations can be found in Figures 4(a) and 4(b). "W" denotes that $\mathrm{M}_{2}$ prefers wholesale price contract, and " $R$ " denotes that $M_{2}$ prefers revenue sharing contract. We can obtain the following observations. (i) In Figure 4(a), if $\lambda=0$, given $M_{1}$ choosing wholesale price contract, $M_{2}$ prefers revenue sharing contract, when $0<\theta \leq 0.55$, otherwise, wholesale price contract. In Figure 4(b), if $\lambda=$ 0 , given $M_{1}$ choosing revenue sharing contract, $M_{2}$ prefers revenue sharing contract, when $0<\theta \leq 0.51$, otherwise, wholesale price contract. This is consistent with Lemma 2. (ii) As the degree of risk aversion increases (e.g., $\lambda>$ 0.19 ), regardless of $M_{1}$ choosing wholesale price contract or revenue sharing contract, it is optimal for $\mathrm{M}_{2}$ to choose the wholesale price contract. A possible reason is that as $\mathrm{M}_{2}$ becomes more and more conservative, he/she tends to avoid the retail price dropping too much $\left(p_{2}^{* \mathrm{RR}}\right.$ is decreasing in $\lambda)$. We obtain equilibrium contract strategies illustrated by Figure 5.

In Figure 5, "RW" denotes that $M_{1}$ chooses revenue sharing contract and $\mathrm{M}_{2}$ chooses wholesale price contract. "RR" denotes that both $M_{1}$ and $M_{2}$ choose revenue sharing contract. We first verify the findings summarized in Theorem 3, that is, "RR" is the equilibrium contract strategy when $0.51<\theta<1$, and "RW" is the equilibrium contract strategy when $0.51<\theta<1$. Then, we find that if the degree of risk aversion and product substitutability are both low, "RR" sustains as the equilibrium contract strategy. Recall that when the competition intensity is low, suppliers tend to keep a relatively low retail price to stimulate demand by adopting revenue sharing contract. However, when suppliers are very conservative, as we have observed, the retail price will become too low. Consequently, $\mathrm{M}_{2}$ may switch to the wholesale price contract, which guarantees a larger profit margin. This differentiates our work from that of Pan et al. [8], in which the impact of risk attitude is not studied.

5.3. Verification with Asymmetric Risk Attitudes (Heterogeneous Risk-Averse Suppliers). In this subsection, we assume that the risk aversion between two suppliers is asymmetric, that is, $\lambda_{1} \neq \lambda_{2}$. Interestingly, given $\mathrm{M}_{2}$ 's choice of wholesale price contract, it can be shown that $\mathrm{M}_{1}$ always prefers revenue sharing contract. Combining our previous findings with symmetric risk attitudes, this phenomenon is rather robust.

Consider the following:

$$
\begin{aligned}
U_{\mathrm{M}_{1}}^{\mathrm{RW}} & -\left.U_{\mathrm{M}_{1}}^{\mathrm{WW}}\right|_{\lambda_{1} \neq \lambda_{2}} \\
= & (\bar{A}-c+c \theta)^{2}\left(4+4 \lambda_{2} \sigma^{2}-2 \lambda_{2} \theta^{2} \sigma^{2}-3 \theta^{2}\right)^{2} \\
& \times\left(2 \theta \lambda_{2} \sigma^{2}+3 \theta+4+4 \lambda_{2} \sigma^{2}\right)^{2} \\
& \times\left(256 \Gamma\left(1+\lambda_{2} \sigma^{2}\right)\left(\Gamma+2 \lambda_{1} \lambda_{2} \sigma^{4}+2 \lambda_{1} \sigma^{2}\right)^{2}\right)^{-1}>0,
\end{aligned}
$$

where $\Gamma=4-2 \lambda_{2} \theta^{2} \sigma^{2}+2 \lambda_{1} \lambda_{2} \sigma^{4}-3 \theta^{2}+4 \lambda_{2} \sigma^{2}+2 \lambda_{1} \sigma^{2}$.

Clearly, $U_{\mathrm{M}_{1}}^{\mathrm{RW}}-\left.U_{\mathrm{M}_{1}}^{\mathrm{WW}}\right|_{\lambda_{1} \neq \lambda_{2}}>0$ always holds regardless of the value of $\lambda_{1}, \lambda_{2}$, and $\theta$.

Now, we analyze $M_{1}$ 's preference given $M_{2}$ 's choice of revenue sharing contract. The parameters are $\bar{A}=1, \sigma=1$, $c=0.5, \theta \in(0,1), \lambda_{2} \in(0,20)$, and $\lambda_{1}=0,0.1$.

As observed from Figures 6(a) and 6(b), when $\lambda_{1}$ increases, it becomes more likely for $\mathrm{M}_{1}$ to choose wholesale price contract. A possible reason is that $M_{1}$ tend to avoid sharply lowered retail price. Another observation is when $\lambda_{2}$ is large, it is better for $M_{1}$ to choose revenue sharing contract. The reason lies in $\mathrm{M}_{2}$ 's possible choice of wholesale price contract when he/she is very conservative. It has been shown that $\mathrm{M}_{1}$ 's optimal strategy is revenue sharing, given $\mathrm{M}_{2}$ 's choice wholesale price contract.

We now also illustrate $M_{2}$ 's preference given $M_{1}$ 's choice under asymmetric risk attitudes. First of all, assuming $M_{1}$ chooses wholesale price contract, we use the following parameters: $\bar{A}=1, \sigma=1, c=0.5, \theta \in(0,1), \lambda_{1} \in(0,20)$, and $\lambda_{2}=0,0.1$. As seen from Figures 7(a) and 7(b), the outcomes can be classified into two distinct regions by the critical curves $f_{g}=0, f_{h}=0, f_{i}=0$, respectively. Again, with larger $\lambda_{2}$, $\mathrm{M}_{2}$ tends to choose wholesale price contract. Assuming $\mathrm{M}_{1}$ chooses revenue sharing contract, the observation is similar.

5.4. Verification with Stochastic Market Variance. In this sub-section, we investigate the role that stochastic market variance $(\sigma)$ plays in the suppliers' contract choices. First, 


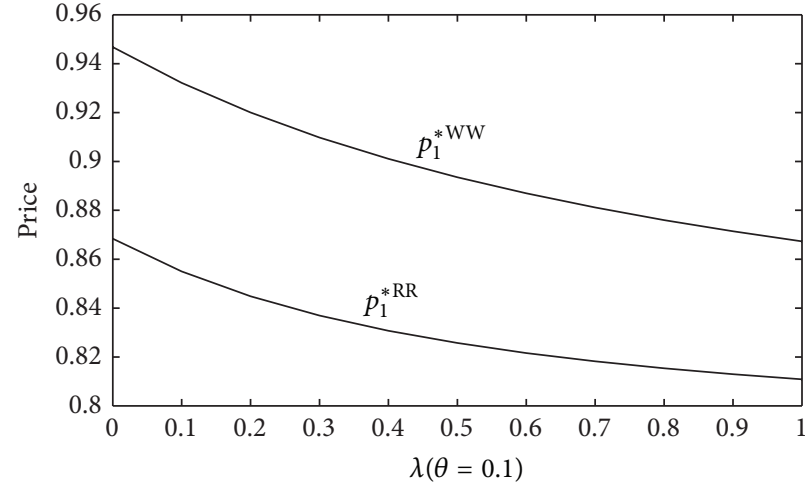

(a)

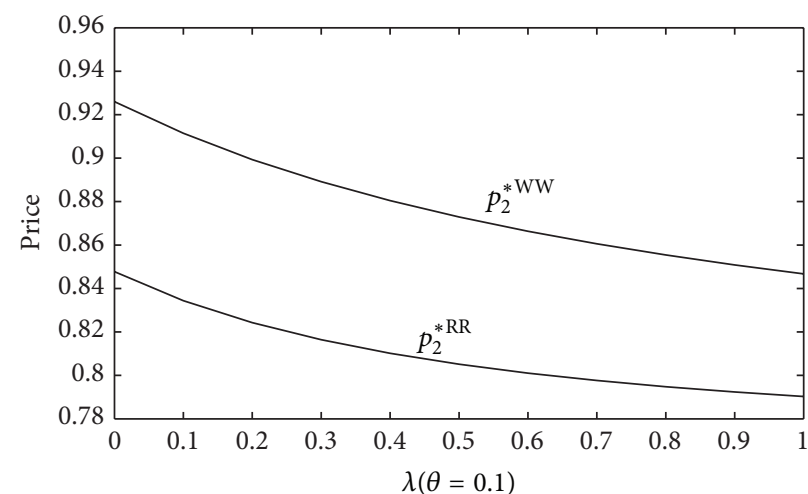

(b)

FIgURE 3: Comparison of the retail prices with $\lambda_{1}=\lambda_{2}=\lambda>0$.

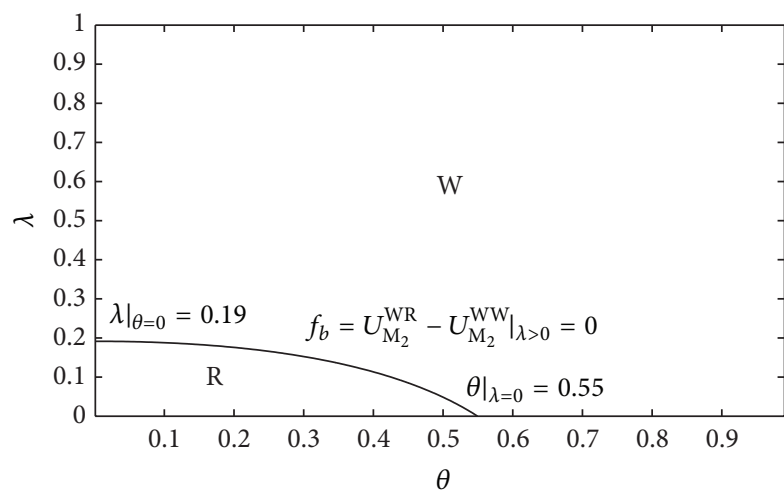

(a)

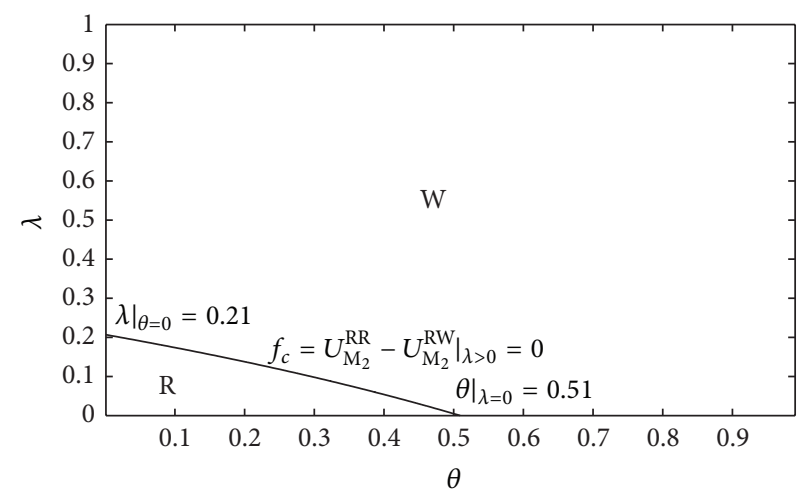

(b)

FigURE 4: (a) $M_{2}$ 's preference given $M_{1}$ 's choice of wholesale price contract $(\lambda>0)$. (b) $M_{2}$ 's preference given $M_{1}$ 's choice of revenue sharing contract $(\lambda>0)$.

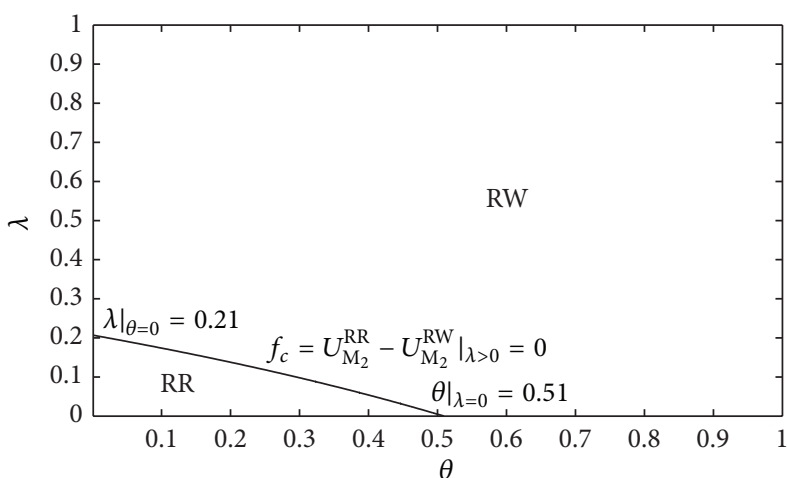

FIGURE 5: Equilibrium contract strategies of suppliers $(\lambda>0)$.

we examine $M_{1}$ 's preference. Given $M_{2}$ 's choice of wholesale price contract, it can be shown that $M_{1}$ always prefers revenue sharing contract. Second, we illustrate $\mathrm{M}_{1}$ 's preference given $M_{2}$ 's choice of revenue sharing contract and $M_{2}$ 's preference given $\mathrm{M}_{1}$ 's choice of wholesale price contract or revenue sharing contract. The parameters are $\bar{A}=1, c=0.5, \theta \in$ $(0,1), \sigma \in(0,2)$, and $\lambda=0.1,0.5$. As seen from Figure 8(a), the rectangular area $\{(\theta, \sigma) \mid 0 \leq \theta<1,0 \leq \sigma<2\}$ is divided into two parts by the curves $f_{j}(\theta, \sigma)=0, f_{k}(\theta, \sigma)=0$, $f_{l}(\theta, \sigma)=0$. In the upper right part (i.e., region I) of the area, all functions $f_{j}(\theta, \sigma), f_{k}(\theta, \sigma)$, and $f_{l}(\theta, \sigma)$ are less than zero. In contrast, in the lower left part (i.e., region II) of the area, all functions $f_{j}(\theta, \sigma), f_{k}(\theta, \sigma)$, and $f_{l}(\theta, \sigma)$ are greater than zero. These observations imply that if the competition density is small and the market variance is also small, revenue sharing contract will be the best option for the two suppliers. This indicates a threshold policy with respect to $\sigma$ for the suppliers to select the contract type. Figure 8(b) shows similar curves. Possible explanation is as follows. Recall that the comparison of the suppliers' utilities depends only on $\theta, \lambda_{i}$, and $\sigma$, and the parameters $\lambda_{i}$ and $\sigma$ always arise together with the form of $\lambda_{i} \sigma^{2}$. Thus, keeping $\lambda_{i}$ as a constant, the impact of $\sigma$ is similar to that of $\lambda_{i}$ shown previously (threshold type).

\section{Conclusion Remarks and Future Research}

In this paper, we consider two sequential-moving supply chains, where each supply chain is composed of one riskaverse supplier and one risk-neutral retailer. We investigate the impact of competition intensity and risk aversion on 


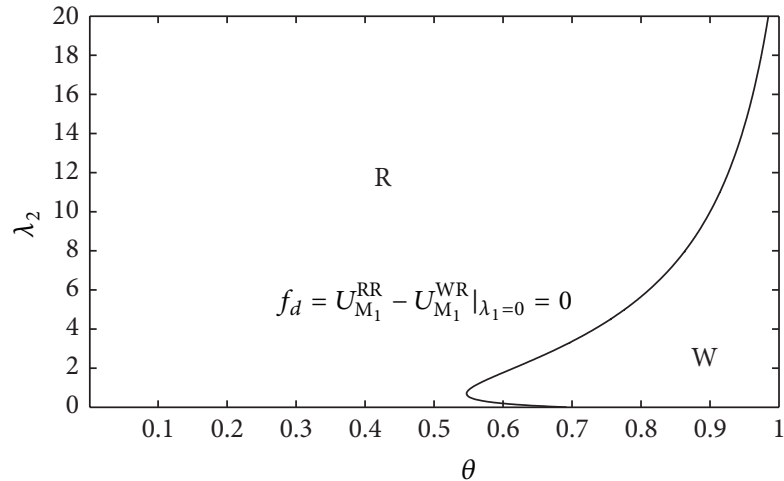

(a)

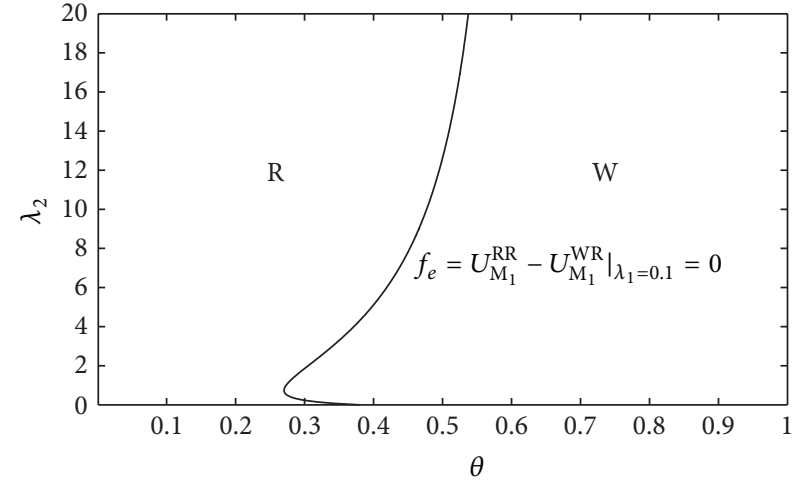

(b)

FiguRE 6: (a) $M_{1}$ 's preference given $M_{2}$ 's choice of revenue sharing contract $\left(\lambda_{1}=0\right)$. (b) $M_{1}$ 's preference given $M_{2}$ 's choice of revenue sharing contract $\left(\lambda_{1}=0.1\right)$.

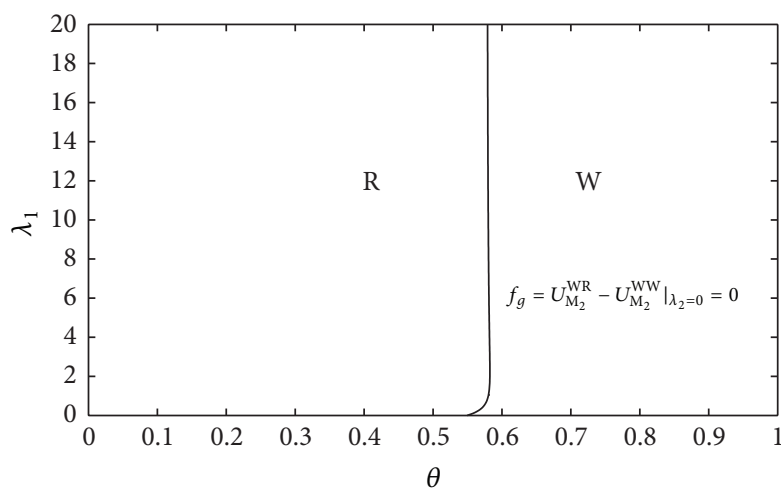

(a)

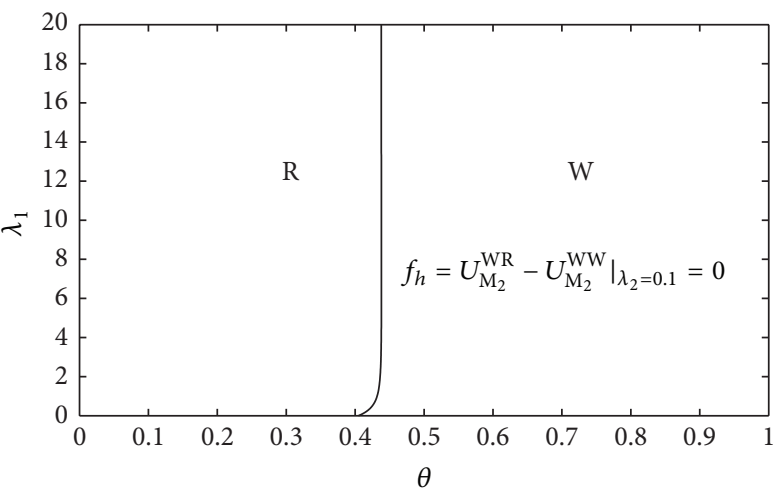

(b)

Figure 7: (a) $M_{2}$ 's preference given $M_{1}$ 's choice of wholesale price contract $\left(\lambda_{2}=0\right)$. (b) $M_{2}$ 's preference given $M_{1}$ 's choice of wholesale price contract under $\left(\lambda_{2}=0.1\right)$.

the contract choice problems. We study by deriving and comparing the equilibriums under the symmetric subgames (including WW and RR case) and hybrid subgames (including WR and RW case), respectively.

Our paper differs from the previous studies of contract choice in two important ways. First, we consider contract choice in the context of two sequential-moving supply chains. Second, we assume that two competing suppliers are riskaverse and analyze how risk aversion of one supplier affects his/her and rival's decisions. We show that the retail prices under revenue sharing contract are lower than that under wholesale price contract. Thus, when the degrees of product substitutability and risk aversion are beyond a threshold value; the second-moving supplier may suffer from too low retail price and hence switch from revenue sharing contract to wholesale price contract. These results complement the current literature that assumes players are risk-neutral and help to explain why sophisticated contracts (e.g., revenue sharing contract) have not completely eliminated the Pareto inferior wholesale-price contract in reality.

We would like to mention two potential directions for future research. First, it is worthy studying the other risk aversion models (e.g., [31, 50]) to see whether our insights hold or not. Second, we have assumed that information is common knowledge. Relaxing this assumption would lead to studies with asymmetric information and would generate insights on the value of information. As Ha and Tong [26] have pointed out, the value of information may significantly influence the choice of contract type.

\section{Appendices}

\section{A. Proof of Lemma 1}

Proof. (i) Given $\mathrm{M}_{2}$ 's choice of wholesale price contract, we compare the utilities of $\mathrm{M}_{1}$ under revenue sharing contract and wholesale price contract as follows:

$$
U_{\mathrm{M}_{1}}^{\mathrm{RW}}-\left.U_{\mathrm{M}_{1}}^{\mathrm{WW}}\right|_{\lambda=0}=\frac{(3 \theta+4)^{2}(\bar{A}-c+c \theta)^{2}}{256\left(4-3 \theta^{2}\right)}>0
$$




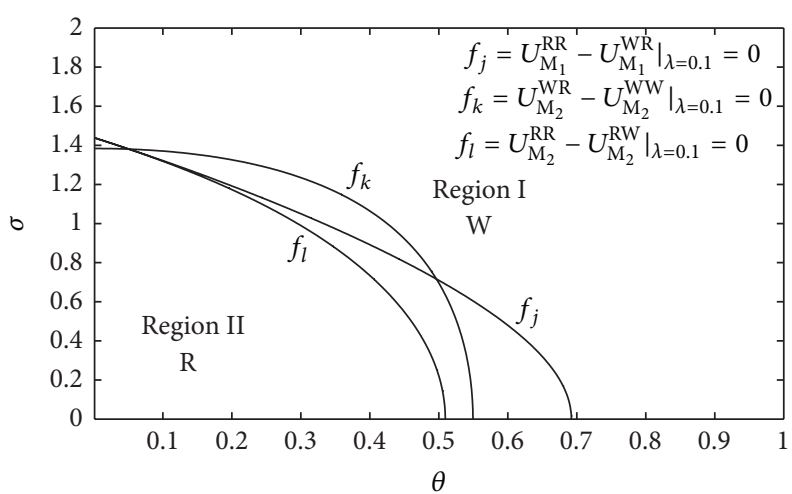

(a)

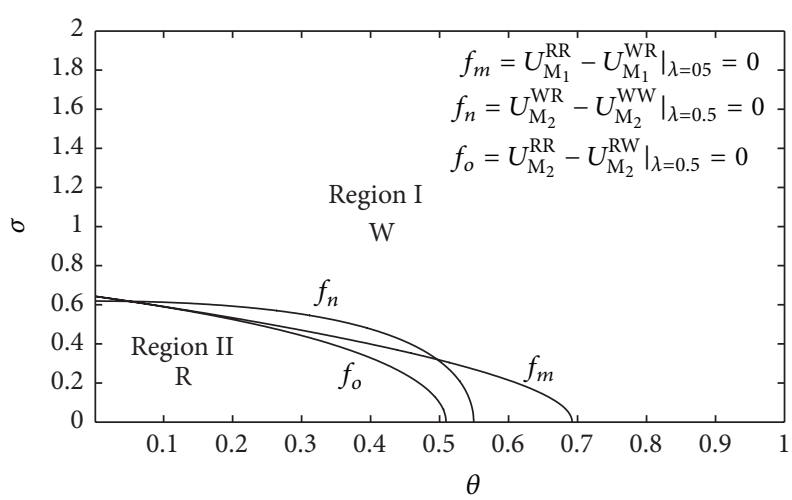

(b)

Figure 8: (a) $M_{1}$ 's and $M_{2}$ 's preference given $(\lambda=0.1)$. (b) $M_{1}$ 's and $M_{2}$ 's preference given $(\lambda=0.5)$.

(ii) Given $\mathrm{M}_{2}$ 's choice of revenue sharing contract, we compare the utilities of $\mathrm{M}_{1}$ under revenue sharing contract and wholesale price contract, finding that

$$
U_{\mathrm{M}_{1}}^{\mathrm{RR}}-\left.U_{\mathrm{M}_{1}}^{\mathrm{WR}}\right|_{\lambda=0}=\frac{(\bar{A}-c+c \theta)^{2} \Phi_{1}(\theta)}{4096\left(2-\theta^{2}\right)\left(4-3 \theta^{2}\right)^{2}},
$$

where

$$
\begin{aligned}
\Phi_{1}(\theta)= & 2048+1024 \theta-4736 \theta^{2}-3712 \theta^{3} \\
& +1616 \theta^{4}+2040 \theta^{5}+441 \theta^{6} \\
= & 441(\theta-1.22)(\theta-0.69)(\theta+1.18) \\
& \times(\theta+1.74)(\theta+1.05)(\theta+2.57) .
\end{aligned}
$$

As $0<\theta<1$, we have $U_{\mathrm{M}_{1}}^{\mathrm{RR}}-\left.U_{\mathrm{M}_{1}}^{\mathrm{WR}}\right|_{\lambda=0} \geq 0$ if $0<\theta \leq 0.69$, otherwise, $U_{\mathrm{M}_{1}}^{\mathrm{RR}}-\left.U_{\mathrm{M}_{1}}^{\mathrm{WR}}\right|_{\lambda=0}<0$.

\section{B. Proof of Lemma 2}

Proof. (i) Given $\mathrm{M}_{1}$ 's choice of wholesale price contract, we compare the utilities of $\mathrm{M}_{2}$ under revenue sharing contract and wholesale price contract and find that

$$
U_{\mathrm{M}_{2}}^{\mathrm{WR}}-\left.U_{\mathrm{M}_{2}}^{\mathrm{WW}}\right|_{\lambda=0}=-\frac{(\bar{A}-c+c \theta)^{2} \Phi_{2}(\theta)}{16384\left(8-10 \theta^{2}+3 \theta^{4}\right)^{2}},
$$

where

$$
\begin{aligned}
\Phi_{2}(\theta)= & 423 \theta^{8}+1800 \theta^{7}-23232 \theta^{6}-56832 \theta^{5}+12224 \theta^{4} \\
& +102912 \theta^{3}+50176 \theta^{2}-24576 \theta-16384 \\
= & 423(\theta-0.55)(\theta-1.28)(\theta-6.7)(\theta+1.07) \\
& \times(\theta+1.33)(\theta+8.77)\left(\theta^{2}+1.62 \theta+0.66\right) .
\end{aligned}
$$

As $0<\theta<1$, we have $U_{\mathrm{M}_{2}}^{\mathrm{WR}}-\left.U_{\mathrm{M}_{2}}^{\mathrm{WW}}\right|_{\lambda=0} \geq 0$ if $0<\theta \leq 0.55$.

Otherwise, $U_{\mathrm{M}_{2}}^{\mathrm{WR}}-\left.U_{\mathrm{M}_{2}}^{\mathrm{WW}}\right|_{\lambda=0} \leq 0$. (ii) Given $\mathrm{M}_{1}$ 's choice of revenue sharing contract, we compare the utilities of $\mathrm{M}_{2}$ with revenue sharing contract and wholesale price contract as follows:

$$
U_{\mathrm{M}_{2}}^{\mathrm{RR}}-\left.U_{\mathrm{M}_{2}}^{\mathrm{RW}}\right|_{\lambda=0}=\frac{(\bar{A}-c+c \theta)^{2} \Phi_{3}(\theta)}{4096\left(8-10 \theta^{2}+3 \theta^{4}\right)^{2}},
$$

where

$$
\begin{aligned}
\Phi_{3}(\theta)= & 81 \theta^{8}-1224 \theta^{7}+488 \theta^{6}+10432 \theta^{5}+6512 \theta^{4} \\
& -15232 \theta^{3}-15104 \theta^{2}+2048 \theta+4096 \\
= & 81(\theta-0.51)(\theta-14)(\theta-3.69)(\theta-1.29) \\
& \times(\theta+1.1)(\theta+1.36)\left(\theta^{2}+1.93 \theta+1\right) .
\end{aligned}
$$

As $0<\theta<1$, we have $U_{\mathrm{M}_{2}}^{\mathrm{RR}}-\left.U_{\mathrm{M}_{2}}^{\mathrm{RW}}\right|_{\lambda=0} \geq 0$ if $0<\theta \leq 0.51$, otherwise, $U_{\mathrm{M}_{2}}^{\mathrm{RR}}-\left.U_{\mathrm{M}_{2}}^{\mathrm{RW}}\right|_{\lambda=0} \leq 0$.

\section{Proof of Lemma 4}

Proof. Consider the following:

$$
\begin{aligned}
& p_{1}^{* \mathrm{RR}}-\left.p_{1}^{* \mathrm{WW}}\right|_{\lambda=0} \\
& =-\frac{(\bar{A}-c+c \theta)\left(32+40 \theta+4 \theta^{2}-9 \theta^{3}\right)}{32\left(8-10 \theta^{2}+3 \theta^{4}\right)}<0, \\
& p_{2}^{* \mathrm{RR}}-\left.p_{2}^{* \mathrm{WW}}\right|_{\lambda=0} \\
& =-\frac{(\bar{A}-c+c \theta)\left(64+80 \theta-4 \theta^{2}-20 \theta^{3}-3 \theta^{4}\right)}{64\left(8-10 \theta^{2}+3 \theta^{4}\right)}<0,
\end{aligned}
$$




$$
\begin{aligned}
& p_{2}^{* \mathrm{RR}}-\left.p_{1}^{* \mathrm{RR}}\right|_{\lambda=0} \\
& =-\frac{\theta^{2}(\bar{A}-c+c \theta)\left(60-2 \theta-39 \theta^{2}\right)}{64\left(8-10 \theta^{2}+3 \theta^{4}\right)}<0, \\
& D_{2}^{* \mathrm{RR}}-\left.D_{1}^{* \mathrm{RR}}\right|_{\lambda=0} \\
& =\frac{\theta^{2}(1+\theta)(\bar{A}-c+c \theta)\left(60-2 \theta-39 \theta^{2}\right)}{64\left(2-\theta^{2}\right)\left(4-3 \theta^{2}\right)}>0 .
\end{aligned}
$$

\section{Acknowledgments}

This research was supported in part by the National Natural Science Foundation of China under Grants nos. 71201175, 71131003, the Youth Foundation of Ministry of Education in China, Humanities and Social Science Research Projects under Grant nos. 13YJC630068, 13YJC630197, and 13YJC630234, the Guangdong Natural Science Foundation under Grants nos. S2012040008081 and S2011040001069, and the 2012 Annual Youth Foundation of Guangdong University of Finance and Economics under Grant no. 12GJPY63001.

\section{References}

[1] J. Zhang, B. Z. Niu, and Q. Fei, "Dynamic quality decisions of software-as-a-service with customer perception," Working Paper, Hong Kong University of Science and Technology \& Guangdong University of Finance and Economics, 2013.

[2] C. Caffarra and F. Mattei, "A theory of contract choices with reference to petrol retailing: risk, incentives and competition," Tech. Rep., The Oxford Institute for Energy Studies, 1994.

[3] Y. Wang, B. Niu, and P. Guo, "On the advantage of quantity leadership when outsourcing production to a competitive contract manufacturer," Production and Operations Management, vol. 22, pp. 104-119, 2013.

[4] Y. Wang, B. Niu, and P. Guo, "The comparison of two vertical outsourcing structures under push and pullcontracts," Forthcoming at Production and Operations Management. In press.

[5] Y. Wang and P. Zipkin, "Agents' incentives under buy-back contracts in a two-stage supply chain," International Journal of Production Economics, vol. 120, no. 2, pp. 525-539, 2009.

[6] D. W. Allen and D. Lueck, "The role of risk in contract choice," Journal of Law, Economics, and Organization, vol. 15, no. 3, pp. 704-736, 1999.

[7] Q. Feng and X. Y. Lu, "Supply chain contracting under competition: bilateral bargaining vs. Stackelberg," Production and Operations Management, vol. 22, no. 3, pp. 661-675, 2013.

[8] K. Pan, K. K. Lai, S. C. H. Leung, and D. Xiao, "Revenue-sharing versus wholesale price mechanisms under different channel power structures," European Journal of Operational Research, vol. 203, no. 2, pp. 532-538, 2010.

[9] G. P. Cachon and A. G. Kök, "Competing manufacturers in a retail supply chain: on contractual form and coordination," Management Science, vol. 56, no. 3, pp. 571-589, 2010.

[10] X. Zhao and C. Shi, "Structuring and contracting in competing supply chains," International Journal of Production Economics, vol. 134, no. 2, pp. 434-446, 2011.
[11] G. P. Cachon, "Supply chain coordination with contracts," in Handbooks in Operations Research and Management Science: Supply Chain Management, A. G. de Kok and S. C. Graves, Eds., Chapter 6, Elsevier, Amsterdam, The Netherlands, 2003.

[12] A. A. Tsay, "Risk sensitivity in distribution channel partnerships: implications for manufacturer return policies," Journal of Retailing, vol. 78, no. 2, pp. 147-160, 2002.

[13] T. W. McGuire and R. Staelin, "An industry equilibrium analysis of downstream vertical integration," Marketing Science, vol. 2, no. 2, pp. 161-191, 1983.

[14] M. Trivedi, "Distribution channels: an extension of exclusive retailership," Management Science, vol. 44, no. 7, pp. 896-909, 1998.

[15] T. Boyaci and G. Gallego, "Supply chain coordination in a market with customer service competition," Production and Operations Management, vol. 13, no. 1, pp. 3-22, 2004.

[16] C. Wu, N. C. Petruzzi, and D. Chhajed, "Vertical integration with price-setting competitive newsvendors," Decision Sciences, vol. 38, no. 4, pp. 581-610, 2007.

[17] D. S. Wu, O. Baron, and O. Berman, "Bargaining in competing supply chains with uncertainty," European Journal of Operational Research, vol. 188, no. 3, pp. 1-9, 2008.

[18] G. Allon and A. Federgruen, "Competition in service industries," Operations Research, vol. 55, no. 1, pp. 37-55, 2007.

[19] B. Y. Shou, J. W. Huang, and Z. L. Li, "Managing supply uncertainty under chain-to-chain competition," Working Paper, City University of Hong Kong, 2009.

[20] C.-H. Chiu, T.-M. Choi, and D. Li, "Price wall or war: the pricing strategies for retailers," IEEE Transactions on Systems, Man, and Cybernetics Part A, vol. 39, no. 2, pp. 331-343, 2009.

[21] G. Xie, S. Wang, and K. K. Lai, "Quality improvement in competing supply chains," International Journal of Production Economics, vol. 134, no. 1, pp. 262-270, 2011.

[22] B. X. Li, Y. W. Zhou, and X. Z. Wang, "Equilibrium analysis of distribution channel structures under power imbalance and asymmetric information," International Journal of Production Research, vol. 51, no. 9, pp. 2698-2714, 2013.

[23] C. J. Corbett and U. S. Karmarkar, "Competition and structure in serial supply chains with deterministic demand," Management Science, vol. 47, no. 7, pp. 966-978, 2001.

[24] F. Bernstein and A. Federgruen, "Decentralized supply chains with competing retailers under demand uncertainty," Management Science, vol. 51, no. 1, pp. 18-29, 2005.

[25] G. P. Cachon and M. A. Lariviere, "Supply chain coordination with revenue-sharing contracts: strengths and limitations," Management Science, vol. 51, no. 1, pp. 30-44, 2005.

[26] A. Y. Ha and S. Tong, "Contracting and information sharing under supply chain competition," Management Science, vol. 54, no. 4, pp. 701-715, 2008.

[27] A. Y. Ha, S. Tong, and H. Zhang, "Sharing demand information in competing supply chains with production diseconomies," Management Science, vol. 57, no. 3, pp. 566-581, 2011.

[28] X. Ai, J. Chen, and J. Ma, "Contracting with demand uncertainty under supply chain competition," Annals of Operations Research, vol. 201, pp. 17-38, 2012.

[29] B. X. Li, Y. W. Zhou, J. Z. Li, and S. P. Zhou, "Contract choice game of supply chain competition at both manufacturer and retailer levels," International Journal of Production Economics, vol. 143, pp. 188-197, 2013.

[30] L. Eeckhoudt, C. Gollier, and H. Schlesinger, "The risk-averse (and prudent) newsboy," Management Science, vol. 41, pp. 786794, 1995. 
[31] V. Agrawal and S. Seshadri, "Risk intermediation in supply chains," IIE Transactions, vol. 32, no. 9, pp. 819-831, 2000.

[32] Y. Wei and T.-M. Choi, "Mean-variance analysis of supply chains under wholesale pricing and profit sharing schemes," European Journal of Operational Research, vol. 204, no. 2, pp. 255-262, 2010.

[33] T.-M. Choi, C.-H. Chiu, and P.-L. Fu, "Periodic review multiperiod inventory control under a mean-variance optimization objective," IEEE Transactions on Systems, Man, and Cybernetics Part A, vol. 41, no. 4, pp. 678-682, 2011.

[34] T. M. Choi, "Multi-period risk minimization purchasing models for fashion products with interest rate, budget, and profit target considerations," Forthcoming at Annals of Operations Research, 2013.

[35] C.-C. Hsieh and Y.-T. Lu, "Manufacturer's return policy in a two-stage supply chain with two risk-averse retailers and random demand," European Journal of Operational Research, vol. 207, no. 1, pp. 514-523, 2010.

[36] O. Caliskan-Demirag, Y. Chen, and J. Li, "Customer and retailer rebates under risk aversion," International Journal of Production Economics, vol. 133, no. 2, pp. 736-750, 2011.

[37] Y.-J. Chen and S. Seshadri, "Supply chain structure and demand risk," Automatica, vol. 42, no. 8, pp. 1291-1299, 2006.

[38] T.-M. Choi, D. Li, and H. Yan, "Mean-variance analysis for the newsvendor problem," IEEE Transactions on Systems, Man, and Cybernetics Part A, vol. 38, no. 5, pp. 1169-1180, 2008.

[39] T.-M. Choi and P.-S. Chow, "Mean-variance analysis of quick response program," International Journal of Production Economics, vol. 114, no. 2, pp. 456-475, 2008.

[40] T. Xiao and T.-M. Choi, "Purchasing choices and channel structure strategies for a two-echelon system with risk-averse players," International Journal of Production Economics, vol. 120, no. 1, pp. 54-65, 2009.

[41] C.-H. Chiu, T.-M. Choi, and X. Li, "Supply chain coordination with risk sensitive retailer under target sales rebate," Automatica, vol. 47, no. 8, pp. 1617-1625, 2011.

[42] C. H. Chiu, T. M. Choi, H. T. Yeung, and Y. Zhao, "Sales rebate contracts in fashion supply chains," Mathematical Problems in Engineering, vol. 2012, Article ID 908408, 19 pages, 2012.

[43] L. J. Ma, F. Liu, S. Li, and H. Yan, "Channel bargaining with riskaverse agent," International Journal of Production Economics, vol. 139, no. 1, pp. 155-167, 2012.

[44] J. Li, T. M. Choi, and T. C. E. Cheng, "Mean-variance analysis of two-echelon fast fashion supply chains with returns contract," Forthcoming at IEEE Transactions on Systems, Man and Cybernetics-Systems, 2013.

[45] L. J. Ma, W. L. Xue, and Y. X. Zhao, "Loss-averse inventory and borrowing decisions with constraints on working capital in fashion and textiles industry," Mathematical Problems in Engineering, vol. 2013, Article ID 657641, 9 pages, 2013.

[46] B. Shen, T. M. Choi, Y. Wang, and C. K. Y. Lo, “The coordination of fashion supply chains with a risk averse supplier by the Markdown money policy," IEEE Transactions on Systems, Man, and Cybernetics-Systems, vol. 43, pp. 266-276, 2013.

[47] C. H. Chiu and T. M. Choi, "supply chain risk analysis with mean-variance models: a technical review," Forthcoming at Annals of Operations Research, 2013.

[48] T. Wang, D. Thomas, and N. Rudi, "The effect of competition on the efficient responsive supply chainchoice," Forthcoming at Production and Operations Management. In press.
[49] T.-M. Choi, D. Li, and H. Yan, "Mean-variance analysis of a single supplier and retailer supply chain under a returns policy," European Journal of Operational Research, vol. 184, no. 1, pp. 356-376, 2008.

[50] Y. Chen, M. Xu, and Z. G. Zhang, "A risk-averse newsvendor model under the CVaR criterion," Operations Research, vol. 57, no. 4, pp. 1040-1044, 2009. 


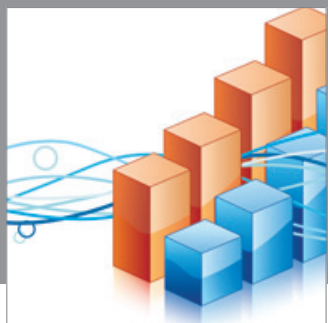

Advances in

Operations Research

mansans

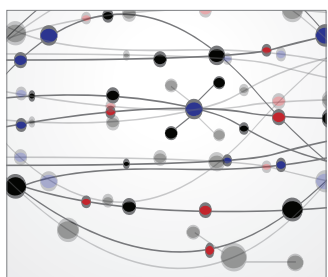

The Scientific World Journal
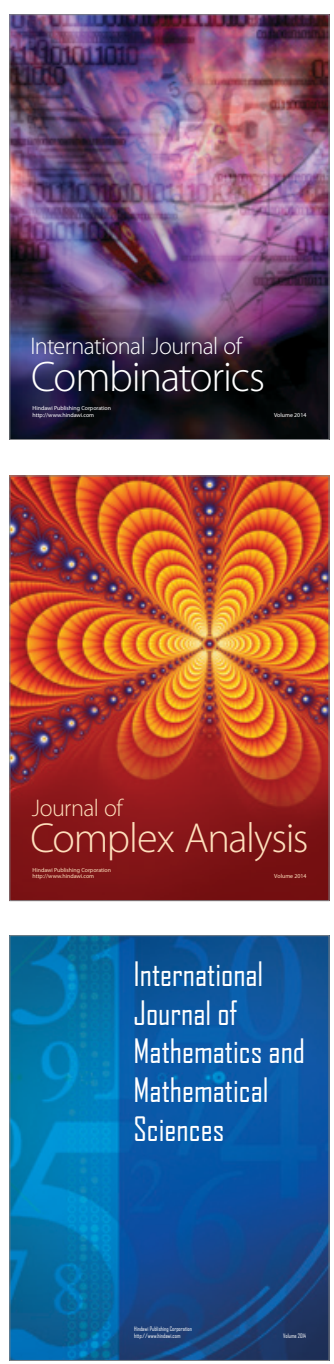
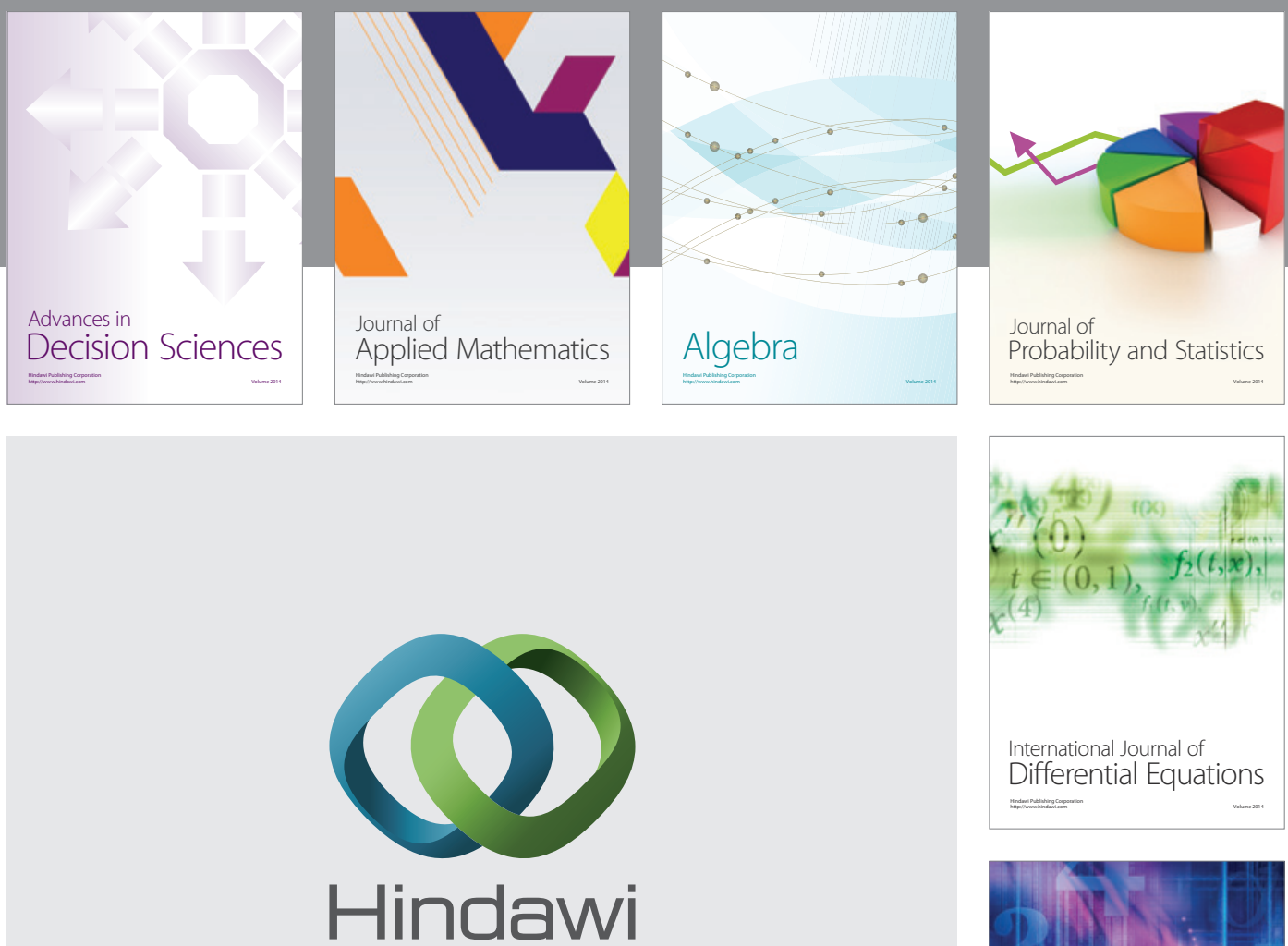

Submit your manuscripts at http://www.hindawi.com
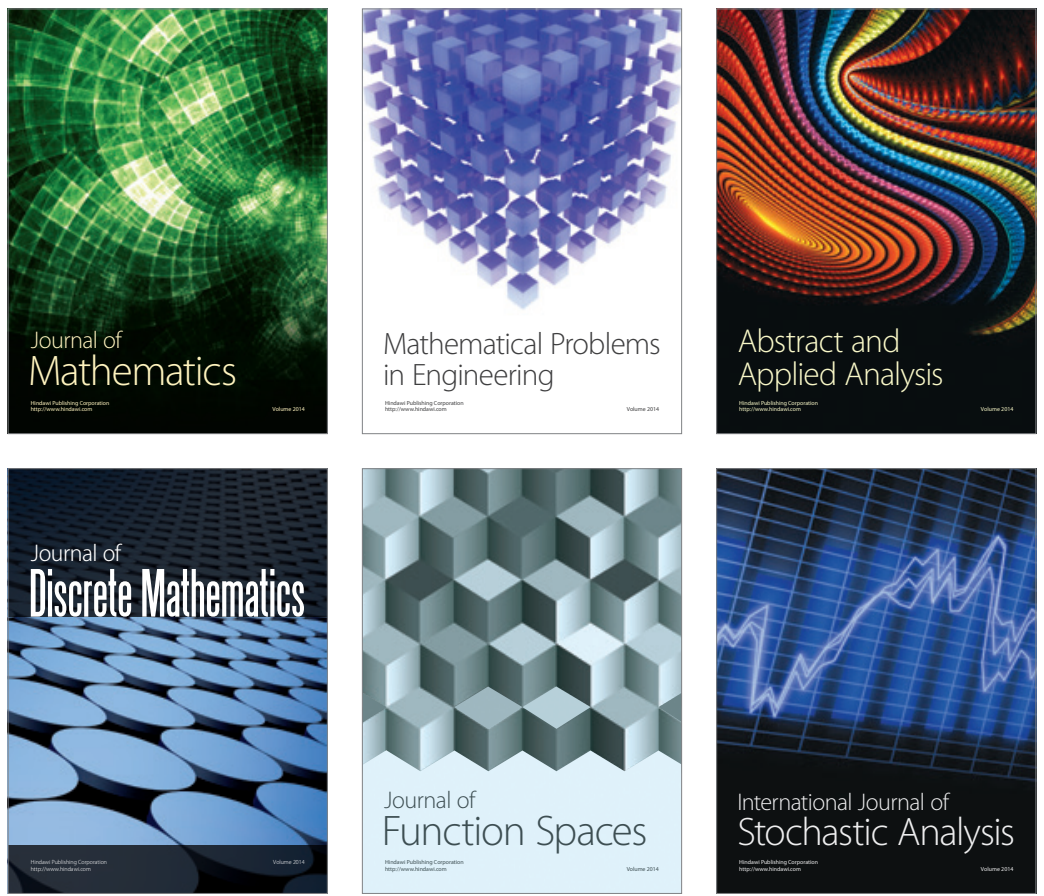

Journal of

Function Spaces

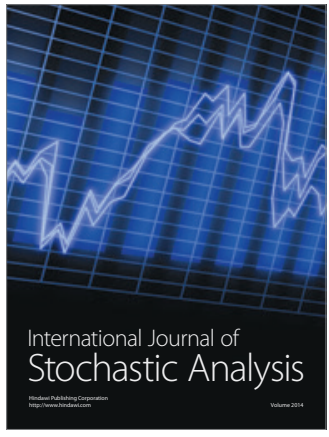

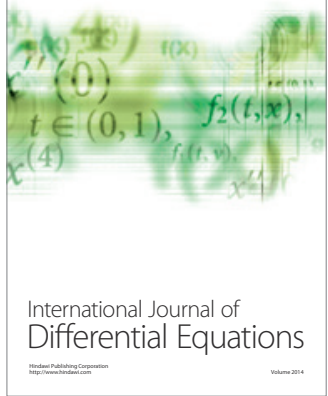
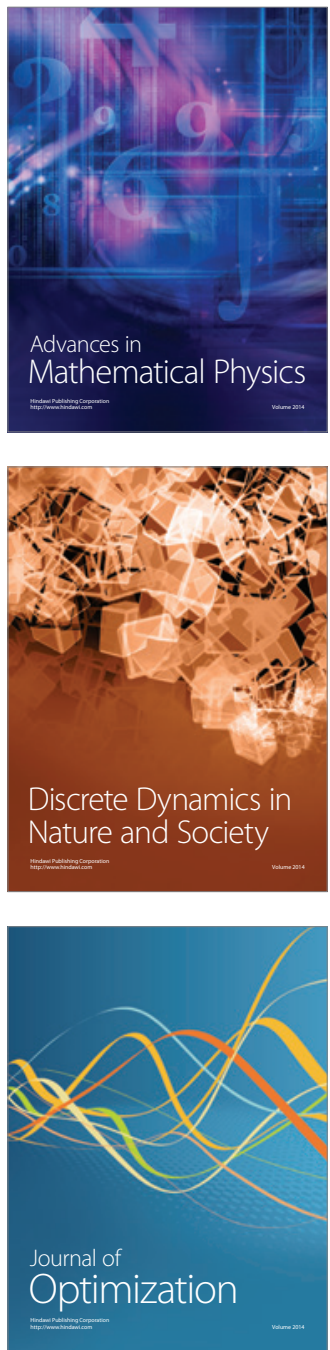